\title{
Student experience with e-Portfolio: exploring the roles of trust and creativity
}

\author{
Rachel Moule \\ Birmingham City University, UK
}

\section{Ethan Rhemahn}

Birmingham City University, UK

\begin{abstract}
Research and pedagogic design for e-Portfolios has tended to focus on optimising the environmental conditions and supportive structures for learners to benefit from more meaningful Personal Development Planning (PDP). Yet engaging students with e-Portfolio for PDP remains difficult.
\end{abstract}

An action research project was undertaken to investigate our learners' experiences with using their e-Portfolio for PDP and to identify what we could learn to inform future design. As part of the project, a focus group interview was undertaken with 8 members of a first year undergraduate cohort who were new to both e-Portfolio and to PDP.

Whilst thematic analysis confirmed other widely reported findings, two strong themes emerged from the focus groups that appear to be less well documented. Although students clearly enjoyed engaging with opportunities for creativity and play, they also expressed uncertainty over the purpose of, and audience, for their e-Portfolio, and thus its academic relevance. The emotional dimension of trust in relation to intended audience, ownership of content, and online space security and accessibility, also emerged as an important student concern and this appeared to act as a barrier to engagement with e-Portfolio.

These findings suggest that engagement with e-Portfolio be reframed to consider more explicit inclusion of the affective dimensions of trust and play as important elements that may encourage a deeper approach to personal learning, and to PDP, through this 
electronic medium. Ways are suggested for tutors to afford opportunities for students to be creative as part of initiation into their e-Portfolio space, and help them to cross an 'affective trust threshold'.

Key words: e-Portfolio; PDP; trust; creativity; engagement.

\section{Introduction}

E-Portfolio literature positions the value of a digital platform as a vehicle for encouraging learners to take control over their own learning, in particular Personal Development Planning (PDP) (Coffey, 2005; Orland-Barak, 2005; Butler, 2006; McMullan, 2006; Haig et al., 2007; Joyce 2005, cited Shepers et al., 2008). Control in this context means enabling them to manage their work in terms of selecting and organising multimedia evidence of learning, and reflecting on and articulating how this amassed evidence demonstrates their personal, academic, professional and ethical development (Barret and Carney, 2005; Hartnell-Young et al., 2007; Buckley et al., 2009).

For all the attendant benefits of e-Portfolio reported in the literature above, the Higher Education (HE) sector is also being informed by a rapidly growing body of literature cataloguing student perceptions of e-Portfolio and in particular potential barriers to the uptake of e-Portfolio (Barrett and Carney, 2005; Tosh et al., 2005; Murray and Smith, 2006; Barrett, 2007). The recurring theme of engagement has emerged as one of the most challenging and potentially problematic issues involved in e-Portfolio curriculum design: studies have tended to focus on optimising the environmental conditions, the balance between ownership and assessment and the implementation of supportive structures (and removal or minimisation of perceived barriers) for learners to engage with their learning in more useful, meaningful ways. Yet studies referenced above still indicate that engaging students with e-Portfolio remains difficult.

Portfolios are based on a constructivist philosophy (Abrami and Barrett, 2005; Klenowski et al., 2006) whereby 'learners construct their own schema for internalizing information and organizing it so that it becomes their own' (Klenowski et al., 2006, p.278). Using this pedagogical model students are not 'merely users of the system; they are, or should be, the authors of it' (Kimball, 2005, p. 442). While the potential for facilitating this kind of 
democratisation is clearly desirable, this pedagogical approach comes with a caveat for its facilitators: shifting the locus of control from the institution to the learner (Acosta and Liu, 2006; Barrett, 2007) may not occur without some degree of (initially at least) uncertainty and potential insecurity/confusion on behalf of the students. Brown et al. (2008) speculated from their findings that self-directed learning places high cognitive demands on undergraduates not found in didactic teaching, in which case care needs to be exercised in the amount of responsibility asked of the student. Whilst some may get educational benefit, others may suffer as a result of being handed such control. Perhaps, therefore, we should be careful not to presume that the adult learning principles driving e-Portfolio are appropriate for all. Overall, however, in contrast to the wide range of literature now available on environmental and design factors, Cambridge and Hartley (2010) highlighted that far less appears to be established in regard to such underlying psychosocial factors and processes which may impede (or support) e-Portfolio take up.

Shepers et al. (2008) raise a number of potentially salient points in a study focusing on 'groupware' such as discussion forums and shared repositories. While such groupware is admittedly not the same as the personalised and potentially private (to greater or lesser degree) platform of e-Portfolio (in which the capacity for facilitating group dialogue may still be embedded) the following issues bear examination.

Interestingly Shepers et. al. (2008) note that every individual constructs their own psychological climate, as perceptions vary according to personal belief paradigms. Psychological safety they conclude, even when using 'groupware' platforms, functions at the individual level of personal perception. Given the potential multiple audiences for their work (for example, personal tutor, course tutor, peers, work-based mentor, potential employer(s), and even family and friends), it is reasonable to assume students would tend to view e-Portfolio technologies in the same way.

Drawing on the work of Dabholkar and Bagozzi (2002) they further posit that a key factor in the formation of this personal psychological climate is the concept of self-consciousness ('a person's view of himself or herself as a social object with an acute awareness of other people's perspectives about him or her' (Dabholkar and Bagozzi, 2002, p.182) and that it comes dominantly into play in any situation characterised by social risk (such as a learning environment which may be either physical or virtual)). 
These concepts would appear to be highly relevant to learners who are engaging with ePortfolio in terms of developing trust as an internalised platform for reflection on and expression of personal, academic and professional identity. Khan (1990) noted that students who feel self-conscious will be fearful of being judged and consequently will be preoccupied with 'managing' how they are perceived in interactions; if e-Portfolio platforms are intended to be a digital projection of identity there is potential for this fear to play itself out in the online arena too. Bearing this in mind the concepts of trust and ownership seem potentially linked and therefore may be important for learner engagement with e-Portfolio.

To get and then keep students engaged with e-Portfolio, Meeus et al. (2006) emphasise the importance of maximising opportunities for individual creativity and self expression, and this is also implied by Kift et al. (2007). However, whilst the importance of one's emotional response to the learning opportunity is established as significant for learning success, evidence to substantiate a link between creativity and engagement with elearning is unclear. Through this study our research objective was to investigate our learners' early experiences with their e-Portfolio, to see what we could learn for future design. Once we better understood how our students experience their e-Portfolio, then we could design for optimising early engagement and subsequently to work with the students to help deepen their learning through the PDP process.

\section{Introducing e-Portfolio within the degree programme}

In 2003 a new programme, BSc Health and Well Being, was developed and validated within a very short period. A decision was made at senior level to use this programme as a vehicle to introduce e-Portfolio, confined to discrete credit bearing PDP modules which would be delivered and assessed in each of three years. E-Portfolio was instigated for the first and second iterations of the semester one, year 1 undergraduate module. Students were drawn from a diverse demographic, congruent with the explicit widening participation agenda followed at Birmingham City University (BCU).

Moodle was deployed as a platform for e-PDP as at the time BCU had not adopted an institutional e-Portfolio. This was not an ideal e-learning situation. Whilst importantly it enabled each student to have design and editorial control over the look, feel and content of their own e-space, technically it was not possible to exclude the two authors from also 
having access to their e-space. Moreover, Moodle was also their designated institutional elearning platform. Student control is congruent with both constructivist pedagogy and our shared philosophical belief in the value of student centred and active learning, for facilitating personally effective PDP, regardless of the medium. However, we recognised from the outset that the platform itself may have to some extent undermined this intent. Following completion of our study, BCU adopted Mahara which, common with other ePortfolios does offer users the necessary level of privacy required for full editorial control.

Early in the module students had dedicated and well supported time to develop their espace, to customise it to their own preferences, which Moodle supports well. They were then encouraged to maintain a reflective learning journal of their personal development progress and to amass evidence of their progress in their other modules. The formative assessment component for e-PDP was a peer-reviewed class-based showcase event of each student's best evidence of their self-identified personal development on the course, together with a short commentary explaining why the evidence was chosen. Peer and tutor feedback on the e-component could then inform the summative assessment task of a 1,000 word progress report on the two personal development needs.

Following an unsuccessful first iteration, for the second iteration we placed more emphasis on the potential value of e-PDP and of effective showcasing to their future employability. We made formative peer review of the showcase a compulsory element but strongly promoted this to the cohort as both a review and a celebration of their achievements on the course to date. The second iteration with 25 students was much more successful in that the majority of students did attempt to develop their e-Portfolio space, did engage with their e-PDP through a structured process and they all passed the module at the first attempt. It is these students' experiences of developing their e-Portfolio which provides the focus for this study.

\section{Study design}

An action research (AR) approach was adopted for this project, as the process is driven by the interplay between ours and our learners' actions, and the intentions behind those actions. Moreover we thought that to adopt a critical approach to our teaching practice we wanted a process that would enable us to try and critically address the values behind our 
practice (Whitehead, 1985). AR within HE has been described by Zuber-Skerritt (1992, p.8) as collaborative critical enquiry by academics themselves into their own teaching practice. Typically within AR as applied to education, educational practices are viewed as social practices to be changed more effectively through collaborative action (Elliot, 1991). We were tasked with implementing, for the context of our institution, a new technology within a new course. As such, and coming to e-Portfolio and e-PDP as novices, we were attracted to McNiff's assertion $(2002$, p.5) that AR may be especially applicable to enquiring into problems of student learning and into curriculum problems that deal with uncertain, unpredictable and multiple realities. This project extended over two full academic years and hence two full AR cycles.

\section{Method of data collection and sampling}

A focus group interview was undertaken with year one students from AR cycle two by one of the authors and forms the focus of this research paper. The method was chosen in order to maximise data capture in a short period of time. Minimising inconvenience to busy students was very important as many have additional work, social and family responsibilities outside of the course. BERA guidelines (2004) were closely followed and ethical approval was obtained through the university's educational research ethics process.

A purposive sampling strategy was deployed. All students were briefed about the reason for the investigation and were approached for permission to participate during an early class session. Participant research information and consent forms were distributed at that point and participants were recruited two weeks later. Students were informed that they were free to withdraw at any point in the research process. Eight students volunteered to participate in a focus group and were broadly representative of the cohort in terms of age, gender and ethnic groupings. The focus group was conducted in a classroom setting immediately following the showcase event just past the mid point of the module, at which the cohort had shared their progress on e-Portfolio and e-PDP with their peers and their tutors (who are the authors). Refreshments were provided as an incentive as this was a lunchtime period. 


\section{Data analysis}

The audiotape was transcribed by the primary researcher and the text was subject to thematic analysis over a period of several weeks. Data was analysed by both authors first separately to identify initial emergent themes and then following a period of reflection on our teaching practice (Van Manen 1977, cited Carlgren et al., 1994) and re-engagement with key literature, together for confirmation of themes and further coding. This approach was adopted to seek to enhance the trustworthiness of the emergent themes (Silverman 2000). We sought to address our potential 'taken for granted' assumptions and loss of objectivity, challenges inherent in insider research where the authors are firmly situated within the world that we study (Denzin, 1997). Our analytic approach was also influenced by Van Manen (1977, cited Carlgren et al., 1994) who emphasised the need for deep reflection and sensitive and repeated reading of the transcript in order to hear and understand the meaning of text for people in a given circumstance, prior to writing an interpretive commentary.

\section{Findings}

Thematic analysis confirmed other widely reported findings regarding the importance of motivating engagement through full integration of e-Portfolio across the curriculum assessment design; striking a suitable balance between formative and summative assessment; and the expectation for tutors to be fully involved and engaged with e-PDP right across the curriculum. Barriers were identified in terms of prerequisite IT skills to enable participation; the imbalance between e-Portfolio interface or design and structure and freedom; the need for adequate time allowance in the curriculum; and one-to-one or small group support to develop those skills in the early stage of the course. There was also a consensus that the e-Portfolio was helping their learning in terms of identifying development needs, enabling them to better focus, (e.g. to identify where more effort was needed), and improving their IT skills. Two themes also emerged that we were not expecting and which are the focus of this section. 


\section{Perceived value of creativity and play}

In response to being asked to describe how they had used their e-Portfolio so far, and what was it like using Moodle to design their e-Portfolio, participants reported engaging with, and very much enjoying, opportunities for creativity in their e-Portfolio space, and this seemed to be linked to exploration of the digital platform. Examples included embellishing their space with favourite pictures, personal musings and hyperlinks to favourite sites for social use, including shopping. Perceived boundaries between creativity, play and academic work were generally fluid.

At the moment l've put a poem on there that l've written previously just to make the page a little bit lighter and I changed some images on there. (Student 6)

I kind of personalised it as well, so even though l've added like academic work and things I think I've improved on and things I need to work on and so forth as well, I've added like all my favourite bits, like I had like a peacock feather background that I absolutely love, and it's just little things to sort of make it personal- but I still go with the academic side. (Student 4)

I tried to kind of mix it as much as could, but I haven't really done too much with it , I'm still kind of getting the hang of it I still don't know how it works fully, so I'm still tweaking, trying to put a picture in, trying to sort of extend it, make it smaller. (Student 2)

It is actually quite fun, it's something that once you get into it, you just don't want to put it away, as there's just so much you can do with it! (Student 5)

In particular several respondents volunteered a sense of getting 'lost in time' on their ePortfolio, and were turning to it to relax from their academic studies. The following quote was from a student who, from tutor review of her e-Portfolio and her subsequent summative assessment, appeared to engage well with e-PDP, so it seems fair to interpret her 'two hours writing rubbish' as a reference to her e-PDP process:

To me yesterday I had a low day, this week has been stressful but going on, um, the e-Portfolio yesterday like after coll - after university, I went back on it and started playing with it. I found that relaxing [sounds surprised] I was like... OK that's 
that's...like going on Facebook'...I don't even need to open a book! [much laughter] so I spend about two hours on it absolute writing rubbish on it! (Student 7)

The majority reported that they were beginning to engage in the e-PDP process, although participants seem to struggle with separating out their broadly enjoyable early experience of engaging with their e-Portfolio from the competing course demands and their own expectations of what it means to be a student in HE:

'Cause it's you know, sort of like, the creative side of our academic side and you can't sit down and spend that much time on it. Even though it's you know a bit of fun, but we've had all these assignments... and that's where you get the academic credit. You just think 'let me get this out of the way and then I can focus on this later'. That's why the creative side has taken more a back step, that for me personally that's how it is - for all of us I think. (Student 4)

For me, it's, um, putting it more bluntly, it's not so serious for me, so putting that in the middle of seriousness, it's just, I can't...I can't do it...I just can't...I need to focus on the more serious things [module assessments]. (Student 5)

\section{Mistrust in the e-Portfolio}

A clear theme that emerged was that students expressed uncertainty regarding ownership of the e-Portfolio and this was related to a lack of trust in the potential multiple natures and purposes of their e-Portfolio:

There's a limit to what you would put on e-Portfolio because it's open to your tutors so... whereas on Facebook you could be more personal with people that you know, you would be guarded with what you put on e-Portfolio because its you know, academically open [chuckles] to you guys [tutors] so better not put that on...whereas on Facebook you're open 'cause you're talking to people you know on a personal level. (Student 6)

I feel it's your space, 'Rachel's still there'. (Student 8)

I put all my stuff in there... oh, I thought it was all mine! (Student 6) 
[There are] possibilities of where it can go - but it's too scary! (Student 1)

Additionally they expressed uncertainty, in the boundaries, permissions and purposes for their e-Portfolio and ultimately, therefore, its academic relevance. Uncertainties over ownership and purpose, particularly linked to uncertainty over which audience their ePortfolio was for, appeared to feed a sense of mistrust and may have caused perceived barriers to engagement with e-Portfolio:

I'm not so sure how good this whole personalising thing is to be honest, because you're trying to...develop something for multiple audiences, one audience is your family and personal, one's the academic, one's the employer, but l'm saying, I don't like that idea, it's like, which audience are you designing it for?...l'd prefer if we are talking academic, it just be that way. (Student 5)

But I don't like the e-Portfolio because everything is so electronically based nowadays, at the touch of a button your whole life is there you know. (Student 6)

\section{Discussion}

Through Moodle many of our students were able to exercise some choices for creatively building and editing their e-Portfolios. Some participants took opportunities for individual expression and expressed clear enjoyment in doing so. Students in the main did speak with great enthusiasm about their positive experiences with, and hopes for, e-Portfolio and what these meant to them (in a way, we have noted in our experience, that typically they tend not to with PDP per se). The mix of enthusiasm and self conscious pride in their early accomplishments on their e-Portfolio, despite the usual barriers and difficulties, and bearing in mind they were not using an e-Portfolio platform as such, is not fully possible to convey in print (due to the role played by verbal emphasis and intonation in their responses), but was independently noted during data analysis by the authors.

The findings suggest that there may be an important relationship between the learner establishing a sense of trust for their ownership of e-Portfolio and their engagement with ePortfolio. This tension may affect students' confidence and ability to engage in e-PDP, 
although we note from Buckley et al.'s (2009) review that users can be simultaneously sceptical about a portfolio's intended purposes and appreciative of what it can deliver for them personally. In our context, the concept of psychological safety may be usefully mobilised to help resolve tensions between private and public space and self expression in an online environment.

Coupled to this (and potentially compounding it) is whether students are trustful of the software itself - of its reliability, security/confidentiality (Joyce 2005, cited Shepers et al., 2008) - and of the intentions for its use - not in just terms of assessment or audience focus but in terms of the aims of the institution who effectively own (corporately) the espace on which their personal portfolios reside (Kimball, 2005). In this sense therefore, applying the cognitive notion of threshold concepts here, the emotion of trust may be helpfully reconceptualised for the users of e-Portfolio as a key affective 'threshold concept' for deep engagement with e-Portfolio. Given the highly personal and individual nature of PDP it is plausible that a sense of trust is also needed for subsequent deep engagement with e-PDP. Further studies could investigate if the effect that we observed using our modified and limited online platform is also an influential factor for student engagement with purpose-built e-Portfolio systems that incorporate learner privacy.

Students (still) need induction to e-Portfolios in a psychologically safe and supported way, both to develop and manage their own online identity for multiple audiences, and to develop both the technical skills and the judgements needed to make the most appropriate uses of the tool/platform to support and record their own learning journey. It may be that this factor has been a little neglected as a topic for e-Portfolio engagement research and practice, in favour of an understandable focus on the central tension of assessment of and for learning and the implications for control and ownership (Tosh et al., 2005, Kift et al., 2007). We argue that increasingly in the modern workplace this is a key skill for employment, and that this may be a growing employability skill, especially in terms of preparing students for self managing their careers, which will for increasing numbers of graduates, in all probability, feature self employment with a series of short term contracts.

When contextualising students' engagement with their e-Portfolio, Csikszentmihalyi's (2002, p.3) conceptualisation of flow may be helpful: 
The state in which people are so involved in an activity that nothing else seems to matter; the experience itself is so enjoyable that people will do it even at great cost, for the sheer sake of doing it.

Csikszentmihalyi (2002) concluded from his studies that the actuality of being in control is not as important as the subjective sense of exercising control in difficult situations. This might explain why our participants reported sometimes experiencing a sense of focussed motivation over their e-space despite also presumably being concurrently aware at a less conscious level, that their institutional e-Portfolio in some way 'belonged' to the university, and was perhaps therefore to be mistrusted - this apparently did not necessarily deter them. Getting into the 'flow' of their e-Portfolio through experiencing the motivational pleasure of creatively playing with the design and other personalisation features also seems to resonate with Biggs' (2003) definition of a deep approach to learning. Although for Biggs, the constructive alignment required to draw the learner in more deeply is implicitly a cognitive experience, we suggest that the affective dimension of human learning also plays a significant role in deepening the learner's approach to e-Portfolio and to e-PDP.

\section{Limitations of the study}

Our use of Moodle had to be significantly modified in order to have some functionality as an e-Portfolio platform; therefore it can be expected that technical and design factors influenced the student experience, and hence their evaluations, more negatively than would have been the case with a dedicated tool. In particular, its perception as an institutional as well as a personal space, and the fact that tutors could see what students can put in, may be anticipated to influence the emergent theme of trust. We acknowledge that this will appreciably reduce the generalisability of our findings from our specific use of a particular e-Portfolio technology.

Our research into student engagement would be richer for being able to continue to collaborate with the students, which may have yielded longitudinal data on their continued engagement with e-Portfolio and experiences of engaging with e-PDP. Unfortunately it was not possible to continue this study due to structural changes within the programme and a change in Programme Director. 


\section{Implications and recommendations}

When engaging with their e-Portfolio it is reasonable to assume that some students will spontaneously use higher cognitive level processes, and will therefore be primed to engage in meaningful personal development. So, we understand that appropriate scaffolding for active learning becomes critical to try to engage as many students as possible in a deep approach to their e-Portfolio, meaning that pedagogic design would be critical. Teaching and learning activities must be closely aligned with course and module outcomes (Biggs, 2003); the challenge for e-Portfolio is essentially no different to paper based or other learning media, which is to strike the right balance between offering supported opportunities for exploration, creativity and individual expression, and supported and structured opportunities for thinking and reflection, in addition to balancing the educational requirements for accountability (i.e. assessment reviewers, summative marks and feedback). Drawing upon our findings, and from our reflections on our own teaching experiences, we have taken the liberty of adapting Biggs' words (2003, p.3); what would a technology of e-Portfolio teaching look like, that maximises the chances of engaging students' learning processes in this way?

Echoing the conclusion of Shepers et al. (2008), our findings suggest that for some, engagement in learning through e-Portfolio involves an element of initial personal risk taking. Where an institutionally hosted platform is used they may be asked to reveal a personal part of themselves, make themselves vulnerable in a potentially public arena. Therefore, extra support may need to be offered to learners to take a leap of faith and cross a threshold of trust to invest themselves. In such situations, we recommend delaying the introduction of more formal processes to facilitate undergraduate e-PDP, in favour of affording supported opportunities for early online exploratory and creative activity. When designing for induction into e-Portfolio and e-PDP, we suggest practitioners give consideration to creating a clearly signposted structure for learners that helps them to cross a 'trust threshold', at their own place. This places the design emphasis on the sequencing exploration in advance of activities such as reflection on learning experiences, peer and tutor assessment and such like, and perhaps even embracing exploration and play as valid learning experiences in their own right.

Practitioner actions to establish a sense of psychological safety should, in theory, support learners to develop a sense of trust when working online. We suggest it is worth 
translating Salmon's (2003) emphasis on the importance of early online socialisation for subsequent learning through asynchronous conferencing to the e-Portfolio platform. A sense of trust could be encouraged through such practitioner behaviours as role modelling, through regular and prompt tutor feedback, through structured and early opportunities for peer feedback, through articulating values, expressed through choice of language verbal and non-verbal communication in the classroom at e-Portfolio launch and training. Clearly these are good practices in the class environment; we simply suggest that when introducing learners to their e-Portfolios extra care can be taken to deliberately reinforce face-to-face expression of these messages in this online environment.

We also recommend that practitioners allow for more time than would be thought for students to simply play with e-Portfolio and explore what they can do with it. It is possible that this could facilitate learners to experience 'flow' in their e-PDP. Clear boundaries for online behaviour, with structured and sequentially increasingly 'risky' activities, in terms of self disclosure, focussed on self-expression online, might encourage longer term and deeper engagement with e-PDP over the duration of the course and beyond. Offer, encourage and celebrate activities that promote creativity (thus signposting academic credibility) but with a clear focus on their ultimate academic purpose(s) and goal(s), and that they have liberty to do this, as a valuable, early and intrinsic part of the PDP process. One action that can be taken to encourage the essential early student buy-in (Tosh et al., 2005), is to emphasise the future value of their e-Portfolio, and indeed using e-Portfolios, for their careers, as well as clearly communicating to students for which audience they are producing specific content.

\section{Acknowledgement}

This paper is an outcome of the National Action Research Network on researching and evaluating Personal Development Planning and e-Portfolio practice project (2007-2010). The project was led by the University of Bolton in association with the University of Worcester and Centre for Recording Achievement, and in national collaboration with the University of Bedfordshire, Bournemouth University and University of Bradford. The project was funded by the Higher Education Academy, National Teaching Fellowship Project strand. More details about the project can be found at:

http://www.recordingachievement.org/research/narn-tree.html. 


\section{References}

Abrami, P.B. and Barrett, H. (2005) 'Directions for research and development on electronic portfolios', Canadian Journal of Learning and Technology, 31(3) [Online]. Available at:http://www.cjlt.ca/index.php/cj|t/article/viewArticle/92/86 (Accessed: 23 August 2010).

Acosta T. and Liu Y. (2006) 'E-Portfolios: beyond assessment', in Jafari, A. and Kaufman, C. (eds.) Handbook of research on e-Portfolios. Indianapolis, USA: Indiana University, pp. 15-23.

Barrett, H. and Carney, J. (2005) Conflicting paradigms and competing purposes in electronic portfolio development. Available at:

http://electronicportfolios.org/portfolios/LEAJournal-BarrettCarney.pdf (Accessed: 23 August 2010).

Barrett, H. (2007) 'Researching electronic portfolios and learner engagement: the REFLECT initiative', Journal of Adolescent and Adult Literacy, 50(6), pp. 436-449.

BERA (2004) Revised ethical guidelines for educational research. Nottingham: BERA. Available at: http://www.bera.ac.uk/files/guidelines/ethica1.pdf (Accessed: 23 August 2010).

Biggs, J. (2003) 'What the student does: teaching for enhanced learning', Higher Education Research and Development, 18(1), pp. 57-75.

Brown, C.A., Dickson, R., Humphreys, A., McQuillan, V. and Smears, E. (2008) 'Promoting academic writing/referencing skills: outcome of an undergraduate e-learning pilot project', British Journal of Educational Technology, 39(1), pp. 140-156.

Buckley, S., Coleman, J., Davison, I., Khan, K., Zamora, J., Malick, S., Morely, D., Pollard, D., Ashcroft, T., Popovic, C. and Sayers, J. (2009) The educational effects of portfolios on undergraduate student learning: a Best Evidence Medical Education (BEME) systematic review. BEME guide no.11. Dundee: AMEE. 
Butler, P. (2006) A review of the literature on portfolios and electronic portfolios. Palmerston North: Massey University. Available at: http://akoaotearoa.ac.nz/community/eportfolios-newzealand/resources/pages/review-literature-portfolios-and-electronic-portfo (Accessed: 28 September 2010).

Cambridge, D. and Hartley, P. (2010) 'Keynote presentation', Second International Residential Seminar: Researching and Evaluating Personal Development Planning and e-Portfolio: CRA/HEA. Nottingham Leadership Centre, Nottingham 25-27 April.

Carlgren, I., Handal, G. and Vaag, S. (eds.) (1994) Teachers' minds and actions: research on teachers' thinking and practice. London: Falmer Press.

Coffey, A. (2005) 'The clinical learning portfolio: a practice development experience in gerontological nursing', Journal of Clinical Nursing, 14, pp. 75-83.

Csikszentmihalyi, M. (2002) Flow: the classic work on how to achieve happiness. London: Rider.

Dabholkar, P.A. and Bagozzi, R.P. (2002) 'An attitudinal model of technology-based selfservice: moderating effects of consumer traits and situational factors', Journal of the Academy of Marketing Science, 30(3), pp. 184-204.

Denzin, N. (1997) Interpretive ethnography: ethnographic practices for the $21^{\text {st }}$ century. London: Sage.

Elliott, J. (1991) Action research for educational change. Buckingham: Open University Press.

Haig, A., Beggs, K., Cadzow, A., Colthart, I., Hesketh, A., Peacock, H. and Tochel, C. (2007) 'Efficacy of e-Portfolios: a systematic review of the evidence', Proceedings from e-Portfolio 2007 Conference. Maastricht 18-19 October. 
Hartnell-Young, E., Harrison, C., Crook, C., Pemberton, R., Joyce, G., Fisher, T. and Davies, L. (2007) Impact study of e-Portfolios on Learning, BECTA evidence and research directorate. Available at: http://partners.becta.org.uk/uploaddir/downloads/page documents/research/impact study eportfolios.pdf (Accessed: 23 August 2010).

Kahn, W. (1990) 'Psychological conditions of personal engagement and disengagement at work', Academy of Management Journal, 33(4), pp. 692-724.

Kift, S., Harper, W., Creagh, T., Hauville, K., McCowan, C. and Emmett, D. (2007) 'EPortfolios: mediating the minefield of inherent risks and tensions', Proceedings $e$ Portfolio Australia: Imagining New Literacies. RMIT University, Melbourne.

Kimball, M. (2005) 'Database e-Portfolio systems: a critical appraisal', Computers and Composition, 22(4), pp. 434-458.

Klenowski, V., Askew, S. and Carnell E. (2006) 'Portfolios for learning, assessment and professional education in higher education', Assessment and Evaluation in Higher Education, 31(3) pp. 267-286.

McMullan, M. (2006) 'Students' perceptions on the use of portfolios in pre-registration nursing education: a questionnaire survey', International Journal of Nursing Studies, 43(3), pp. 333-43.

McNiff, J. and Whitehead, J. (2002) Action research principles and practice. New York: RoutledgeFalmer.

Meeus, W., Questier, F. and Derks, T. (2006) 'Open source e-Portfolio development and implementation of an institution-wide electronic portfolio platform for students', Journal of Educational Media International, 43(2), pp. 133- 145.

Murray, C. and Smith, A. (2006) 'From application to graduation and beyond: user engagement in the e-Portfolio process', EDEN Conference Proceedings, pp. 211216. Available at: http://www.elp.ac.uk/downloads/eden\%20ELP\%20paper.pdf (Accessed: 23 August 2010). 
Orland-Barak, L. (2005) 'Portfolios as evidence of reflective practice: what remains untold', Educational Research, 47(1), pp. 25-44.

Salmon, G. (2003) E-moderating: the key to learning and teaching online. $2^{\text {nd }}$ edn. London: Taylor Francis.

Shepers, J., De Jong, A., Wetzels, M. and De Ruyter, K. (2008) 'Psychological safety and social support in groupware adoption: a multi level assessment in education', Computers in Education, 51(2), pp. 747-775.

Silverman, D. (2000) Doing qualitative research: a practical handbook. London: Sage.

Tosh, D., Light, T.P., Fleming, K. and Haywood, J. (2005) ‘Engagement with electronic portfolios: challenges from the student perspective', Canadian Journal of Learning and Technology, 31(3) [Online]. Available at:

http://homepages.ed.ac.uk/jhaywood/papers/Engagement $\% 20$ with\%20Electronic\%2 OPortfolios.pdf (Accessed: 23 August 2010).

Whitehead, J. (1985) 'An analysis of an individual's educational development: the basis for personally orientated action research', in Shipman, M. (ed.) Educational research: principles, policies and practices. Contemporary analysis in education: series 8. London: Falmer, pp. 97-108.

Woodward, H. and Nanholy, P. (2004) 'Digital portfolios, fact or fiction?', Assessment and Evaluation in Higher Education, 29(2), pp. 227-238.

Zuber-Skerritt, O. (1992) Action research in higher education: examples and reflections. London: Kogan Page.

\section{Author details}

Rachel Moule is a Senior Academic (Learning and Teaching) in the Centre for Health and Social Care Research, Faculty of Health, Birmingham City University. Rachel 
provided e-Portfolio design and technical support for learners on the module in her capacity as e-Portfolio project lead for the BCU CETL: Centre for Learning Partnerships. The focus group research reported in this paper was undertaken by Rachel for a MA Higher Education module of study.

Ethan Rhemahn is an Education Facilitator in the Personal Development Centre, Faculty of Health, Birmingham City University. Ethan is experienced in teaching and facilitating Personal Development Planning and was the module lead on this project.

Both are members of the National Action Research Network on Researching and Evaluating Personal Development Planning and e-Portfolio Practice, and as such, this Action Research project was undertaken within the auspices and support infrastructure of the network. 